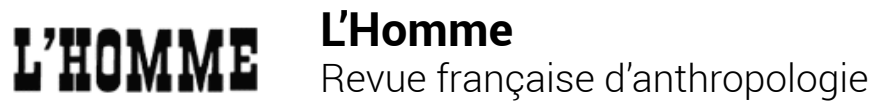

187-188 | 2008

Miroirs transatlantiques

\section{Helena Dembsky, ed., Kronike iz Limba : zgodbe prosilcev za azil}

(Chronicles from Limbo : Stories of Asylum Seekers)

\section{Yazid Ben Hounet}

\section{(2) OpenEdition \\ Journals}

Édition électronique

URL : https://journals.openedition.org/lhomme/21052

DOI : 10.4000//homme.21052

ISSN : 1953-8103

Éditeur

Éditions de l'EHESS

Édition imprimée

Date de publication : 3 octobre 2008

Pagination : 535-536

ISBN : 978-2-7132-2186-6

ISSN : 0439-4216

\section{Référence électronique}

Yazid Ben Hounet, « Helena Dembsky, ed., Kronike iz Limba : zgodbe prosilcev za azil », L'Homme [En ligne], 187-188 | 2008, mis en ligne le 16 décembre 2008, consulté le 23 avril 2022. URL : http:// journals.openedition.org//homme/21052 ; DOI : https://doi.org/10.4000/lhomme.21052

Ce document a été généré automatiquement le 23 avril 2022.

(c) École des hautes études en sciences sociales 


\title{
Helena Dembsky, ed., Kronike iz Limba : zgodbe prosilcev za azil
}

(Chronicles from Limbo : Stories of Asylum Seekers)

\author{
Yazid Ben Hounet
}

\section{RÉFÉRENCE}

Helena Dembsky, ed., Kronike iz Limba : zgodbe prosilcev za azil (Chronicles from Limbo : Stories of Asylum Seekers). Ljubljana, Etno je fletno, 2007, 331 p., bibl., gloss.

1 En août 2008, a eu lieu à Ljubljana (capitale de la Slovénie) le $10^{e}$ congrès de l'Association européenne des anthropologues sociaux (EASA). À celles et ceux intéressé(e)s de près ou de loin par le sort des demandeurs d'asile, je leur conseillerais ce livre. Kronike iz Limba n'est certes pas un travail scientifique indispensable ni même majeur - là n'est pas la prétention des éditeurs -, mais c'est en tant qu'œuvre de témoignages, d'information et de mise en perspective des évolutions de la situation des requérants d'asile en Slovénie (pays peu connu), et plus largement en Europe, que l'ouvrage mérite une attention particulière. Le livre, écrit en quatre langues (slovène, croate, anglais et italien) se compose de neuf témoignages de demandeurs d'asile (huit hommes et une femme) et d'une introduction dans laquelle sont notamment présentées les évolutions des mesures politiques prises à leur égard en Slovénie, d'une préface, d'un glossaire et d'une courte bibliographie. L'ouvrage réalisé par des jeunes étudiantschercheurs fait suite à une journée d'étude et d'échanges qui eut lieu le 16 décembre 2005 au sein du Département d'ethnologie et d'anthropologie culturelle de l'Université de Ljubljana. Entre décembre 2005 et février 2006, le sujet est réapparu sur la scène publique slovène en raison de la préparation d'une nouvelle loi (Act Amending the Asylum Act) autrement plus dure à l'égard des demandeurs d'asile et malheureusement adoptée en février 2006.

2 Comme le signalent Helena Dembsky et Ursula Lipovec-Cebron dans leur introduction, un fait particulièrement nouveau s'est produit à l'occasion des débats concernant cette 
loi : les demandeurs d'asile jusqu'alors simples témoins passifs, « objets » de recherches ou "sujets » de reportages médiatiques sont apparus en tant que véritables acteurs, c'est-à-dire en tant que personnes parlant pour elles-mêmes et organisées en vue de la défense non pas de leurs "intérêts » (on s'en doute, il ne s'agit pas là d'un groupe privilégié) mais plus simplement et plus tristement en vue de la défense de leur dignité en tant qu'êtres humains. Et c'est cet aspect que l'ouvrage met le mieux en perspective en nous livrant ces témoignages. Les chercheurs s'effacent alors pour nous laisser mieux percevoir la réalité des conditions de vie des demandeurs d'asile, narrées par les premiers concernés. On reste alors confondu par certains récits (tel celui de Jasmin) et par l'absurdité et la dangerosité des mesures prises à leur égard en Slovénie et plus largement en Europe (notamment celles de la convention de Dublin).

3 La méthode des témoignages, des morceaux de récits de vie, permet une approche autrement plus sensible du sujet. On perçoit mieux cette réalité sans doute triviale mais que l'on a souvent tendance à oublier: les demandeurs d'asile sont avant tout des hommes et des femmes « intégraux » (pour reprendre la formule de Virgil Gheorghiu) ${ }^{1}$, des individus avec leurs parcours, leurs souffrances, leurs affects et leurs espoirs... et non pas seulement des « demandeurs d'asile » (comme si cette catégorie pouvait encore les définir). La méthode permet enfin et surtout de donner la parole à celles et ceux que l'on entend encore malheureusement trop peu. «les classes [ou groupes] dominées ne parlent pas, elles sont parlées » écrivait fort justement Pierre Bourdieu². J'ose croire que l'un des rôles de l'ethnologue est d'aller à l'encontre de cette forme de domination en donnant autant que faire se peut la parole aux individus et groupes qu'il est censé " étudier »- surtout lorsque ceux-ci sont largement " parlés ». C'est en tout cas l'un des paris de Kronike iz Limba. C'est aussi pour cela que l'ouvrage mérite que l'on s'y attarde.

\section{NOTES}

1. Virgil Gheorgihu, La Vingt-Cinquième Heure, Paris, Plon, 1949.

2. «Une classe objet », Actes de la recherche en sciences sociales, 1977, 17-18 : 4. 